\title{
Aspectos da Capacidade Ociosa na Função Pública
}

JOSÉ AUGUSTO GUERRA

Professor da Universidade de Brasília. Escritor

Debruçados sôbre gráficos e projeções, alguns técnicos têm destinado muito de seu tempo a um problema que adquire novas dimensões à proporção que a máquina administrativa se amplia: que fazer da mão-de-obra ociosa do serviço público?

Para uns, quebra-cabeça insondável e insolúvel. Não adianta fazer nada. A solução virá por si mesma, com o tempo. Para outros, motivo de elocubrações que penetram nas ínvias esferas doutrinárias da sociologia e da economia. E principalmente para os homens de govêrno, uma questão de implicações tão sérias na política de investimento e na política orçamentária que, apesar das fórmulas até agora sugeridas para enfrentar o problema, não se chegou ainda a uma conclusão satisfatória.

$\mathrm{Na}$ verdade, conviria saber se a premissa de que se parte é verdadeira; se o princípio da ociosidade, como vem sendo posto, corresponde à realidade administrativa do País e se a figura do ocioso não será efeito (e não causa) do esquema administrativo. Sejam quais forem os ângulos por que se procure estudar a matéria, vamos encontrar cabeças e sentenças doutrinando e opinando, até resultar numa legislação cujos efeitos nem sempre têm correspondido às intenções primeiras.

\section{REGRAS E EXCEÇÕES}

Não convém jogar pedras no passado. Sabemos que a chamada política de pessoal nem sempre corresponde às exigências da legislação específica. Os textos legais proibindo o ingresso de servidores sem concurso são tranqüilamente furados pelo próprio legislador que admite a possibilidade de exceções a fim de fugir à regra. Ora, quando uma lei admite exceções, em nome das justas necessidades administrativas, é geralmente por 
esta janela que se possibilita o ingresso de quantos sejam necessários ao desempenho da função pública. De modo que, recordar leis, decretos, portarias, em suma, a legislação que trata da ociosidade, seria o mesmo que remoer águas passadas ou ainda correntes, sem nenhum proveito.

$\mathrm{Na}$ prática, o legislador anda certo quando admite as exceções. E se o administrador, no uso de suas prerrogativas, vai além, ainda assim não se afasta do texto legal quando admite "por necessidade absoluta do serviço público", mais alguns servidores para os quadros ministeriais ou autárquicos. E se formos, em sã consciência, examinar as razões das admissões novas, veremos que o administrador está mesmo necessitando de pessoal, seja ou não qualificado.

\section{A MAIS RECENTE EXPERIENCIA}

Acontece que a chamada ociosidade funcional não se manifesta com maior incidência na faixa de pessoal melhor classificado. O grande pêso está no funcionalismo de escalão inferior. E como êsse funcionalismo constitui legião, fere os olhos de quem visita certas repartições públicas a visão um tanto caótica de mesas e cadeiras que se acotovelam e seus funcionários não parecem corresponder ao serviço existente. A chamada máquina burocrática, por excesso de artesãos, funciona com dificuldade. A burocracia amplia seus passos. E o velho expediente do ao-ao é ainda norma genérica, apesar dos esforços de quantas entidades promovem cursos de aperfeiçoamento e especialização para servidores, como o DASP e a Fundação Getúlio Vargas.

Embora seja êste um retrato administrativo que remonta a muitas décadas, tem-se procurado cortar o excesso de pessoal admitido e já considerado estável, através de providências tècnicamente bem arquitetadas mas de resultados pouco felizes.

Estamos lembrados da mais recente providência: a Lei no 5.413 , de 10 de abril de 1968, "que institui, em caráter temporário, a licença extraordinária". O funcionário com mais de 4 anos de efetivo serviço e cuja substituição não fôsse necessária até 30-6-69, podia pedir licença de no mínimo 1 ano até 3 anos, com prorrogação até 6 anos. Afastado do cargo, perceberia nos três primeiros anos importância não inferior a $50 \%$ de seus vencimentos e vantagens adicionais; e do quarto ao sexto ano da ausência, êste vencimento de ocioso seria reduzido à metade. 
O legislador raciocinou com uma lógica que não nos parece de funcionário público, mas de empregador de emprêsa privada. Admitiu, com tôda a segurança, que alguns milhares de ociosos tranqüilamente agradeceriam essa possibilidade de se afastarem do serviço público a fim de se dedicarem a outras funções, sem a perda do vínculo funcional; e mais: ainda levando vantagem, com a percepção de parte considerável dos vencimentos.

Vimos os resultados: pífios. Sabe-se que se uma dezena de requerimentos de ociosos chegou a ser encaminhada, é muito. E para tão pouca colheita, tendo em vista o que se esperava, não valeu a pena elaborar tal legislação.

\section{RAZÕES DO INSUCESSO}

Por que isso aconteceu? Algumas razões. Se o funcionário é excedente em sua repartição, e se tal condição não o impede de tratar de seus interêsses particulares, muito melhor continuar como está do que passar recibo de ocioso, com requerimento do próprio punho. Ocioso dentro ou fora das normas funcionais, preferível não se afastar de suas funções. Além disso, com as prerrogativas que a legislação permite, melhor utilizá-las, do que afastar-se do cargo com inseguras possibilidades de retôrno.

$\mathrm{Na}$ justificativa oferecida pelos técnicos do Ministério do Planejamento ao projeto encaminhado à consideração do Congresso Nacional, salientava-se que "o problema da capacidade ociosa no Serviço Público" não poderia ficar à espera de uma "solução global". E continuava: "Encontra-se nesse caso a possibilidade de estimular os servidores, cuja presença se torne desnecessária, a se integrarem, voluntária e progressivamente, nas atividades privadas, aliviando, simultâneamente, os cofres públicos, que dêsse modo poderão melhor recompensar os esforços daqueles que exercem atividade produtiva; e, de outro lado, assegurar recursos para investimento, mediante a redução dos gastos de custeio."

Observe-se, do ponto de vista psicológico, que o legislador, reconhecidamente, atribuía ao funcionário que procurasse beneficiar-se da lei uma característica nada louvável: sua presença era desnecessária. E embora lhes acenasse (mera hipótese) com a possibilidade de uma integração no complexo industrial privado, logo que deixasse o serviço público, marcava-lhes na testa $o$ sinête - ocioso. 
Extinta a vigência da Lei no 5.413 , complementada pelos Decretos nos 62.665, de 8 de maio de 1968, e 63.512, de 31 de outubro de 1968, pode-se hoje admitir que a ausência de requerentes não significa a inexistência de ociosos no Serviço Público. Significa antes a revelação de que ou o mercado de trabalho industrial e comercial não está em condições de absorver novos contingentes, ou o ocioso, porque profissionalmente inqualificado, tem receio de não encontrar acolhida fora da função pública.

Além disso, um tanto anômalo o caminho encontrado para desobrigar-se a Administração Pública do "pêso morto" de certas categorias funcionais. Fortes razões econômicas teriam determinado a fórmula figurada na Lei $n ? 5.413$. Mas, percebe-se hoje, poder-se-ia ter evitado o insucesso da medida se precedida de um estudo sistemático da situação do pessoal da Administração, já objeto de exame pela atual direção do DASP. Na conferência pronunciada recentemente pelo Prof. Glauco Lessa de Abreu e Silva, Diretor-Geral do DASP, sob o título O DASP e a Reforma Administrativa, entre as providências em andamento no quatriênio 70/73, constam: "Item V - Levantamento sistemático da carga de trabalho das diferentes unidades administrativas, fixação de lotações correspondentes e instituição de normas para absorção de pessoal considerado excedente, de forma a conter o ingresso de pessoal nos justos limites; $\mathrm{VI}$ - Organização do Sistema de Pessoal, situando-se os diversos órgãos administrativos que o compõem em conjunto funcional, relacional e comunicacional" (in Revista do Serviço Público, Vol. 105, no 1, jan./abril 1970).

Só nesses dois itens se encontra um vasto programa de trabalho, sem o que não se pode cogitar de qualquer estruturação de política de pessoal. Primeiro, conhecer a realidade administrativa nacional pelo conhecimento "da carga de trabaIho das diferentes unidades administrativas"; a seguir, a "organização do Sistema de Pessoal".

PSICOLOGIA DO ÓCIO

Se a capacidade ociosa na Administração Pública é um fato notório - embora ainda não rigorosamente medido e contado - de quem a responsabilidade?

Quando o funcionário toma posse sua primeira intenção é servir. Por que ocorre a estranha metamorfose de transformar- 
se, passados alguns anos, ou nem tanto, num funcionário idêntico a tantos outros, aprendendo até para ensinar as manhas profissionais? De bisonho servidor, em estágio probatório, transforma-se, sem nenhuma razão aparente, num funcionário igual a tantos outros, medíocre, simples cumpridor de meia-dúzia de tarefas que se repetem diàriamente, e, ao cabo de pouco tempo, tendo assimilado os vícios da espécie, torna-se indolente, desinteressado, quando não dominado pela preguiça.

(Sentado em sua mesa, recebe papéis, carimba, examina, passa adiante, levanta-se, vai ao cafèzinho, volta, abre um processo, necessita consultar a legislação mas o manual não está à mão, ficou na estante da chefia, não é conveniente sair agora e apanhar a lei, vamos a um papo e esperar um pouco, agora pode ir fazer a consulta, mas é hora do lanche, outro cafèzinho, além disso tem aquêle telefonema importante, depois consultará a legislação, embora haja decreto mais recente, e nesse caso só a própria assessoria do Ministro poderá resolver, então passa-se o processo adiante, o que é mais recomendável, e por que preocupar-se, ora essa, se faltam vinte minutos para terminar o expediente, é bom ir arrumando a mesa.)

Estabelece-se assim a rotina, no dia-a-dia tranqüilo e monótono. E o dinamismo de quem, lá fora, há poucos meses, tinha garra e entusiasmo, para vencer, para realizar alguma coisa, converte-se numa cinzenta abulia. Em pouco tempo, nosso funcionário se sente mais uma roda, mais um parafuso inútil na engrenagem administrativa. $O$ que faz durante o longo período do expediente poderia ser tranqüilamente realizado em quinze, vinte minutos, quando muito uma hora. $\mathrm{E} o$ resto do tempo? Tempo considerado ocioso.

\section{NA ESCALA DO ÓCIO}

De quem, entretanto, a responsabilidade maior?

Não será do escriturário, do datilógrafo, do técnico de administração, por certo. Nem do nosso cartógrafo ou do arquivista. Entretanto, a ociosidade compreende uma classificação tão curiosa quanto surpreendente. Porque na escala do ócio há muitas razões. Vejamos algumas.

Z., funcionário da Seção de Pessoal, recebe uma tarefa que realiza em poucos minutos. Que fazer do resto do tempo? Ou se entrega às palavras cruzadas; ou "dá uma voltinha" para resolver assuntos de seu interêsse fora da repartição; ou se entrega à parolagem sôbre a loteria esportiva. E porque outros colegas 
se encontram em situação semelhante, vamos preencher as horas com o disse-me-disse. Esta é a ociosidade mais conhecida, mais típica - por excesso de pessoal.

Entretanto, Z. tem aptidões louváveis e quociente intelectual revelador de imaginação e capacidade. Cedo, aborrece-se com a tarefa por demais simples. Considera-se frustrado, enquanto (e aí Z. mergulha no mundo das comparações), tantos colegas, mais falantes, extrovertidos, dentro em pouco alcançam situações melhores. Rebentam em Z. aos poucos, e depressa amadurecem, os sinais de desinterêsse, resistência às tarefas recebidas e inaptidão. Conflitos se armam, sutis a princípio, mais sérios no correr do tempo. E, bastam alguns meses, é o próprio $Z$. quem se surpreende como desajustado, e, portanto, sem possibilidades de produzir. Cai na maledicência. Um ocioso por desajustamento psicológico.

"Evidentemente - pensa Z. - eu não devia ter aceito esta função. Afinal, sou estudante de Medicina e me entregam esta tarefa de carimbar papéis de protocolo. Podia estar na secretaria do Distrital. É o fim."

Z. precisava de um emprêgo para custear os estudos. Conseguiu o emprêgo e abandonou os estudos no terceiro ano de Medicina. Atualmente em suas conversas, a Medicina é tema de parolagem. Lembra-se de um ou outro episódio ocorrido durante as aulas. Quando na repartição alguém tem problemas no fígado ou uma dor de cabeça mais forte, consulta $Z$., o que fêz metade do curso de Medicina. $Z$, não se perdoa. Lastima a hora em que entrou para o serviço público. Carimba com fôrça o papel. Surpreende-se soltando palavrão. E, no fim do dia, verifica que nada fêz, nada produziu. Ocioso. Sim senhor, um ocioso por inadaptação vocacional.

Z. pode ser também aquêle funcionário, inteligência briIhante (é o que ouve, constantemente, quando apresentado a outras pessoas), mas seu chefe imediato é um burocrata fiel, rígido, implacável, obediente ao ponto, embora tolerante com o que possa acontecer durante o expediente. Conhece Z., ouve falar de sua capacidade, mas situa-se no esquema de classificação de cargos - "oficial administrativo é oficial administrativo e não passa disto". E, entre dentes: "Se a gente der asas a êsses rapazes considerados inteligentes, êles terminam mandando aqui dentro e pondo as manguinhas de fora". Isolado, $Z$. cumpre sua magra tarefa. E se confunde com os demais, no 
cafèzinho, nas fugas, na parolagem, no negativismo: é ocioso por deficiência de chefia.

Quem foi êste senhor, o dr. Z.? "Já dirigiu muita coisa, no tempo do Ministro X. Agora está aí, não faz nada."

Funcionário capaz, por longos anos devotado (devotadíssimo, diria o José Dias, de Machado de Assis), Z. assumiu e deu conta de algumas funções de relêvo. Goza atualmente de prestígio. Exatamente o prestígio advindo do passado, das posições assumidas, é que the confere esta situação, para muitos cômoda, para êle incômoda, de não fazer nada. Encostado, anda pelos corredores, conta piadas, toma cafèzinho nos gabinetes, recorda os "bons tempos", mete-se na biblioteca da repartição e, após meio expediente, de consciência tranqüila, volta para casa, assinado o livro de freqüência. É o ocioso por condescendência, permissão, tolerância ou consentimento de quem lhe é superior.

Mas Z. pode também ser ocioso por decisão pessoal: produz o mínimo, o suficiente, e só. Acha que trabalhou demais para tantos governos e aguarda a aposentadoria tranqüilamente. Pode ainda, motu proprio, organizar o seu horário. Torna-se ocioso por falta de função adequada ao seu status.

\section{QUEM É RESPONSAVEL?}

Um técnico de administração observaria que tudo isso ocorre no Serviço Público devido à falta de racionalização, de distribuição racional de trabalho. (Racionalização - expressão que se emprega hoje em tudo, sem que seus efeitos tenham alcançado, com êxito, a Administração Pública.)

$O$ caso de $Z$., em suas formas diversas, um tanto caricatas, afasta do próprio personagem a responsabilidade maior pelo que lhe ocorre na condição de servidor público. Sua ociosidade, a ociosidade de que é acusado, decorre de fatôres que the escapam inteiramente.

Z. não está roubando o tempo à repartição se, cumprida a tarefa, começa a debater a próxima rodada da loteria esportiva. Seu desinterêsse, seus conflitos interiores bem poderiam ser superados por um processo de ajustamento psicológico. $O$ conflito interior, muito íntimo, pode ser superado com atribuições semelhantes à linha vocacional. Um chefe, se merece êste nome, não deve temer funcionários mais capazes e dêles até poderá colhêr subsídios importantes à sua gestão. E o velho Z., por 
que não voltar a prestigiá-lo na organização de serviços afins com a administração? E se é Z. quem organiza por conta própria o seu horário, então estamos no caos administrativo. Mais uma vez, nosso ocioso não é responsável. A própria infra-estrutura funcional lhe permite cometa desatinos.

CONCLUSÃO

Em face dessas considerações, já estamos inclinados a admitir que a ociosidade na Administração Pública não é uma soma de problemas pessoais, mas uma questão diretamente vinculada ao esquema administrativo. Ocioso, causa e não efeito do sistema - eis um raciocínio inteiramente despropositado. Ele existe, o ocioso, sem dúvida. Mas a origem de sua presença remonta a outras fronteiras.

Pacífica a constatação, entre os estudiosos da matéria, que não existe, a rigor, excesso de funcionários. Se considerarmos que as necessidades administrativas estão constantemente exigindo a admissão de novos contingentes de pessoal; se deficiente é a situação no interior do País em áreas de precária prestação de serviços; então falar de ociosidade como fator relevante, torna-se, no caso, irrelevante e até ocioso.

Se ao DASP compete, por lei, a tarefa de renovar o sistema administrativo, o estudo da chamada capacidade ociosa deve ocupar planos de maior evidência. Mas não será cortando na carne do funcionário dito ocioso; antes, reformulando os esquemas burocráticos, com a finalidade de solucionar algumas das fontes da ociosidade - estruturas inadequadas, repartições mal dirigidas, legislação caduca, pessoal despreparado.

Em si mesma, a capacidade ociosa é uma conseqüência da desvalorização da função pública e do próprio servidor. Mas não terá, a médio prazo, nenhuma razão de existir, se partirmos da premissa oposta à com que se tem abordado o problema. Se ocorre a desvalorização da função pública, haja vista, em têrmos de status a posição que ocupa o funcionário no contexto social, cumpre valorizá-la através de uma política que, em primeiro plano, coloque a produtividade funcional ao nível de serviços prestados ao Estado. Provàvelmente isto não se fará num abrir e fechar de olhos. Mas não vamos olhar o tempo como um fantasma de alguns andares impedindo que se desentulhe o caminho. Se pouco se fêz até agora, muito resta fazer. Não por falta de teorização, já abundante, para não dizer excessiva. Mas por falta de quem se predisponha a levar a sério a tarefa, com o espírito largo de quem se desatavie dos labirintos burocráticos e parta para decisões realmente construtivas. 